\title{
An Impact Study on Vocational Training Programme on Milky Mushroom Farming
}

\author{
Gurram Ranjitha*, Jillela Teza and A. Veeraiah
}

Krishi Vigyan Kendra, Utukur, Kadapa, Andhra Pradesh 516003, India

*Corresponding author

\section{A B S T R A C T}

\section{Keywords}

Mushroom, KVK,

Vocational, Knowledge,

Mass media, Adopters,

Spawn

Article Info

Accepted:

12 October 2018

Available Online:

10 November 2018
Krishi Vigyan Kendras - KVKs (Farm Science Centres) had been established by Indian council of Agricultural Research (at present there are $695 \mathrm{KVKs}$ under XI ATARIs). Imparting vocational trainings for entrepreneurship development for women, rural youth and farmers is one of the mandate of KVKs. The present study was conducted on evaluating the effectiveness of vocational trainings on Mushroom cultivation held at Krishi Vigyan Kendra (KVK), Utukur conducted which is needed for further improvement in their standard. A structured interview schedule consisting of statements related to their socio economic profile. Formative evaluation was done by taking reaction and knowledge test to get outcome of the training. Summative evaluation was conducted to know the adoption status of mushroom cultivation enterprise by the trainees, the problems faced by them in adoption of this enterprise and economic impact of adoption growers. A typical trainee was a young, married, educated, low annual income, from nuclear family and nonagricultural and urban background, have no experience in mushroom farming and are highly participating through mass media are keen to adopt mushroom cultivation for additional income. Reaction of trainee regarding various aspects of teaching- learning situations of the training programmes viz., trainer, subject matter, teaching material and physical facilities was taken. It was understood that the teaching material should be improved with photographs where ever necessary and colour printout of booklet can be supplied. Also, it was identified that, prior to the training, the trainees were less aware with respect to their knowledge and understanding about the mushroom cultivation aspects. But after the training, there is significant increase in the knowledge level of trainees. All the trainees had positive change in the level of knowledge after the training. Adoption status of mushroom cultivation was studied to know the impact of vocational training programmes. It is indicated that 80 percent of the trainees had adopted mushroom cultivation enterprise and various problems faced by mushroom growers were Non remunerative price (42\%), Non availability/ poor quality of spawn (38\%) lack of proper infrastructure (20\%). About $45 \%$ of continued adopters had increased their family income by $60-80 \%$ followed by $30 \%$ of continued adopters had increased their family income by $5-10 \%$. Further, it was confirmed that mass media played major role in facilitating the information regarding imparting of vocational training based on the feedback of trainees. 


\section{Introduction}

India facing most challenging task of sustaining the farmers income with the increasing pressure on land for more production per unit area. However, in India, 70 per cent of the productive farming land is mainly under the small and marginal farmers. Small and marginal farmers are unable to keep pace with rapid technology advances in agriculture and increase their productivity as they lack knowledge and skill regarding the new technologies presently available. Hence, capacity building and imparting entrepreneurship skills to the farmers, women and rural youth has become one of the most important mandate of the extension system of India. Therefore, Krishi Vigyan Kendras which are well established and approachable extension units of extension system of India, available in almost all the districts of India are directed to organize vocational training programmes for small and marginal farmers' especially rural youth (Anonymous 2015) to augment farmers' income from the limited resources available from agriculture and allied activities. Krishi Vigyan Kendra, Utukur, Kadapa under the administration of Acharya $\mathrm{N}$ G Ranga Agricultural University has taken up the vocational training programme of Mushroom farming for building entrepreneurship skills in the rural farmers, women and youth. Mushroom farming is considered as a crucial component for food safety and security. The consumption of mushrooms was increasing at faster rate with the changing lifestyle, food habits, increase in awareness among people on nutritional and health benefits of mushroom assuring food safety to the increasing human population.

Mushroom farming is taken up as vocational training programme, as it is considered to provide security to rural poor by providing additional income, thus alleviating the poverty in rural areas and confronting educated unemployment in urban and semi urban areas. It is a subsidiary low cost occupation grown as an indoor crop, by utilizing vertical space and obtaining more productivity per unit area. Hence, KVK Utukur, Kadapa had created awareness on mushroom cultivation among the rural people through mass media, and many rural had contacted KVK for training of mushroom farming. Thus, training on mushroom has cultivation had become one of the important flagship programme of KVK, Utukur Kadapa aiming at facilitating the trainees on mushroom production technology and entrepreneurship development. Six vocational training programmes were conducted on mushroom cultivation at Krishi Vigyan Kendra, Utukur from 2015 to 2018. About, 180 trainees were trained on the basic concepts of cultivation of milky mushroom cultivation. However, Evaluation of training programmes is needed for the knowing its the utility and effectiveness offered to the community (Astoth, 1991; Butler 1991; Johnson and Verma, 1990) and also for further improvement of the training programme.

Evaluation also helps to answer the questions on accountability, effectiveness, relevance and strategies about the training programmes (Suvedi, 2011). With this objective, the present study was designed to evaluate the effectiveness of vocational trainings on Mushroom cultivation held at Krishi Vigyan Kendra, Utukur, Kadapa.

\section{Materials and Methods}

This study was conducted at Kadapa district of Andhra Pradesh. A sample of 50 active trainees participated in trainings of mushroom farming at KVK, Utukur, Kadapa from 201516 to 2017-18 were selected.

A structured interview schedule consisting of statements related to their socio economic profile. The response of trainees towards 
teaching- learning situations of the training programmes and knowledge test were evaluated to get outcome of the training by formative evaluation. Summative evaluation was conducted to get impact of the training by knowing the adoption status of mushroom enterprise by the trainees, the problems faced by them in adoption of this enterprise and economic impact of adoption growers. (Singh et al., 2010)

For evaluating socio economic profile of trainees, 10 aspects viz., age, sex, marital status, education, family type family background family occupation, annual income mushroom production experience and mass media participation were considered.

For evaluating reaction of trainees regarding various aspects of teaching- learning situations of the training programmes, trainer (Fluency, clarity in speech, language), subject matter (Relevance, appropriateness), teaching material (literature, websites) and physical facilities (food and sitting arrangements) were taken into consideration.

To evaluate knowledge test, pre and post training knowledge scores of the respondents with respect to various mushroom cultivation practices viz., types of mushrooms, nutritive value in mushroom, availability of spawn, methods of substrate making, moisture content, temperature to be maintained, spawning method, no of holes per bag, sterilization of unit, no of days in darkroom, no of days in light room, harvesting methodology, preservation method, pests and disease management, importance of casing, marketing channels, awareness on availability of loans and subsidies from government, income, BC Ratio, value addition to mushrooms were evaluated.

To evaluate adoption status, relative position of a respondent regarding adoption, non- adoption and discontinuation with the enterprise and non-adoption of enterprise was taken. The data regarding adoption status and problems faced in adoption was taken through telephone and personal contact.

To evaluate economic impact, the percentage increase in household income with mushroom enterprise after participating in vocational training was taken into considered.

\section{Statistical analysis}

Evaluation was done based on the tool developed by Kay Rockwell (1999) and followed by Mahantesh et al., (2016), Nagaraj et al., (2017) and Dharminder Singh and Singh (2016). Formative evaluation measure the outcome of training and summative evaluation measure impact of training.

Socio economic profile of the respondents was evaluated using simple statistical tool viz., frequency and percentage.

Likert- type items such as reaction of trainees regarding various aspects of teaching- learning situations of the training programmes were measured using Descriptive statistics. Each of the variables was measured with Likert-type items with 5 as the highest score and 1 as the lowest score.

Knowledge test of participants regarding different sub components of mushroom farming was evaluated by conducting pre and posttest. Pretest was conducted to know how much the trainees have knowledge on various aspects of mushroom farming. Similarly, after completion of training post evaluation was performed in order to assess the knowledge gained by the trainees. Pre and post evaluation test was conducted for the participants using 20 structured questionnaires. One and zero score was assigned for the correct and incorrect responses respectively and the 
maximum attainable score is 20 and converted in percentage.

Overall knowledge of the respondents was calculated using Paired t-test.

Adaption status, problems faced in mushroom farming and Economic status of the respondents was evaluated using simple statistical tool viz., frequency and percentage

\section{Results and Discussion}

\section{Socio economic profile}

Out of 180 participants, a sample of 50 trainees actively participated in the training were selected. 41 trainees represented different mandals of kadapa district and 9 were from other districts of Andhra Pradesh. The distribution of respondents based on socio economic profile is given in Table $1(n=50)$.

Training participants were young (62\%), medium aged (32\%) and $6 \%$ were more than 50 years age. Among them, male (56\%), female $(44 \%)$ and $64 \%$ of them were married.

The education level of them up was quite high as majority of the trainees $(66 \%)$ studied above matriculation. Most of the participants were from urban and non-agricultural background with nuclear family. Few (12\%) had a gross monthly income of more than Rs 10,000. (Figures in parenthesis are in percentage and rounded off to the nearest whole number).

From Table 1, it is inferred that a typical trainee was a young, married, educated, low annual income, from nuclear family with nonagricultural and urban background, having no experience in mushroom farming and are highly participating through mass media are keen to adopt mushroom cultivation for additional income.

\section{Formative evaluation}

Reactions of trainees towards various aspects of the training programme

Trainees were asked to give their reaction regarding various aspects of teaching- learning situations of the training programmes viz., trainer, subject matter, teaching material and physical facilities and the data is tabulated in Table 2.

For trainer - Fluency, clarity in speech, language were considered.

For subject matter content - relevance, appropriateness were considered.

For teaching material - literature, websites were considered.

For physical facilities- sitting and food arrangements.

The participants response was largely found satisfied with the subject matter $(M=4.88$, $\mathrm{SD}=0.09$ ) content taught to them in the training programme followed by the fluency and clarity in speech of the trainer $(\mathrm{M}=4.80$, $\mathrm{SD}=0.20$ ). Further, it is also indicated that the trainees were satisfied with the training facilities ( $M=4.44, \mathrm{SD}=0.39)$ comparatively.

Trainees are least satisfied to teaching material ( $\mathrm{M}=4.16, \quad \mathrm{SD}=0.41)$ among all the four variable. The arithmetic mean for teaching material was found relatively low compared to other variables. The range of the individual variable was 1.70 (3.2-4.9) shows that there is relatively wide range of opinion among the trainees about the training material.

Further, during feedback it was understood that the teaching material should be improved with colour photographs where ever necessary and colour printout of booklet can be supplied. 


\section{Knowledge gain}

Different topics (Praveen Kumar et al., 2018) in the training covering the types of mushrooms, nutritive aspects of mushrooms, raw materials availability, substrate preparation, cultivation, crop protection, harvesting, post-harvest management, marketing and economics. Pre and post evaluation test was conducted for the participants by using 20 structured questionnaires. One and zero score was assigned for the correct and incorrect responses respectively and the maximum attainable score is 20 . The gain in knowledge was reflected in terms of difference between number of trainees giving correct responses before and after the training programme. Paired t-test was applied to measure the impact of training with respect to their overall knowledge level of the trainees.

The data in Table 3 pertains to pre and post training mean knowledge scores of the respondents with respect to various mushroom cultivation practices. The pre training mean knowledge score of various practices ranged from 0 to 6 out of 20 and that of post training mean knowledge score of various practices ranged from 16 to 20 out of 20. It can be seen that more number of trainees was able to give correct response regarding various mushroom cultivation practices after attending the training programme.

\section{Overall knowledge gain}

From Table 3, the arithmetic mean of pretraining test was 9.5 and increased to 91.5 after training with the variance of 97.11 and 34.47 respectively. The $t$ values of difference between pre and post training mean knowledge score of all the practices of mushroom farming were significant $(p<0.01)$. Post evaluation scores of gain in overall knowledge about various practices indicate
65-100 \% improvement in their knowledge. The results showed that, prior to the training, the trainees were less aware with respect to their knowledge and understanding about the mushroom cultivation aspects. But after the training, there is significant increase in the knowledge level of trainees. All the trainees had positive change in the level of knowledge after the training. Gain in knowledge about various mushroom practices was also reported by Goel et al., (2013), Singh and Singh (2016).

\section{Impact evaluation}

The Impact Evaluation is summative in nature. It is conducted to assess the impact of vocational training. Adoption status of the trainees was considered the indicator for the impact evaluation.

\section{Adoption status}

Adoption status of mushroom cultivation was studied to know the impact of vocational training programmes and was measured in terms of continued adopters, discontinued and non-adopters of mushroom cultivation enterprise. From the Table 4, it is indicated that 80 percent - of the trainees had adopted mushroom farming where as 20 percent did not adopt. Singh and Singh (2016) reported high number of non-adopters in mushroom cultivation vocational training programmes of KVK. But in this study, the continued adopters were maximum. Problems in mushroom farming are presented in Table 5.

It can be observed that various problems faced by mushroom growers were non remunerative price $(42 \%)$, non-availability or poor quality of spawn (38\%) lack of proper infrastructure (20\%). Jahan et al., (2010) and Singh and Singh (2014) also reported the problems of non-availability or poor quality of spawn and lack of assured marketing. 
Table.1 Socio economic profile of the respondents participated in the training

\begin{tabular}{|c|c|c|c|}
\hline S No & Characteristics & Frequency & Percentage \\
\hline \multirow[t]{4}{*}{1} & Age & & \\
\hline & Young (less than 30 years) & 31 & 62 \\
\hline & Medium (31-50 years) & 16 & 32 \\
\hline & Old (more than 50 years) & 03 & 06 \\
\hline \multirow[t]{3}{*}{2} & Sex & & \\
\hline & Male & 28 & 56 \\
\hline & Female & 22 & 44 \\
\hline \multirow[t]{3}{*}{3} & Marital status & & \\
\hline & Married & 32 & 64 \\
\hline & Unmarried & 18 & 36 \\
\hline \multirow[t]{4}{*}{4} & Education & & \\
\hline & Illiterate and primary & 03 & 06 \\
\hline & Upto Matriculation & 14 & 28 \\
\hline & Above matriculation & 33 & 66 \\
\hline \multirow[t]{3}{*}{5} & Family type & & \\
\hline & Nuclear & 41 & 92 \\
\hline & Joint & 09 & 18 \\
\hline \multirow[t]{3}{*}{6} & Family background & & \\
\hline & Rural & 11 & 22 \\
\hline & Urban & 39 & 78 \\
\hline \multirow[t]{3}{*}{7} & Family occupation & & \\
\hline & Agriculture & 14 & 28 \\
\hline & Other & 36 & 72 \\
\hline \multirow[t]{4}{*}{8} & Annual income & & \\
\hline & Low (less than Rs 50,000 ) & 34 & 78 \\
\hline & Medium $(50,000$ to $1,00,000)$ & 10 & 20 \\
\hline & High (above Rs 1,00,000) & 06 & 12 \\
\hline \multirow[t]{4}{*}{9} & Mushroom production experience & & \\
\hline & low & 46 & 84 \\
\hline & medium & 4 & 8 \\
\hline & high & 1 & 2 \\
\hline \multirow[t]{4}{*}{10} & Mass media participation & & \\
\hline & low & 2 & 4 \\
\hline & medium & 7 & 14 \\
\hline & high & 41 & 82 \\
\hline
\end{tabular}


Table.2 Response of trainees to different topics and training facilities with respect to the variables

\begin{tabular}{|l|l|l|l|l|l|}
\hline $\mathbf{S}$ & Variables & Range & Median & Mean & $\begin{array}{l}\text { Standard } \\
\text { Deviation }\end{array}$ \\
\hline $\mathbf{1}$ & Trainer (Fluency, clarity in speech, language) & $4.0-5.0$ & 4.85 & 4.80 & 0.20 \\
\hline $\mathbf{2}$ & subject matter content (Relevance, appropriateness) & $4.7-5.0$ & 4.90 & 4.88 & 0.09 \\
\hline $\mathbf{3}$ & teaching material (literature, websites) & $3.2-4.9$ & 4.20 & 4.16 & 0.41 \\
\hline $\mathbf{4}$ & physical facilities (sitting and food arrangements) & $3.5-5.0$ & 4.40 & 4.44 & 0.39 \\
\hline
\end{tabular}

Table.3 Gain in knowledge after acquiring training with respect to different operations

\begin{tabular}{|c|c|c|c|c|}
\hline $\begin{array}{l}\text { S } \\
\text { No }\end{array}$ & Particulars & $\begin{array}{l}\text { Pre evaluation } \\
\text { Score out of } 20\end{array}$ & $\begin{array}{l}\text { Post evaluation } \\
\text { Score out of } 20\end{array}$ & $\begin{array}{l}\text { Improvement in } \\
\text { knowledge Score } \\
\text { out of } 20\end{array}$ \\
\hline 1 & Types of mushrooms & $4(20)$ & $19(95)$ & $15(75)$ \\
\hline 2 & Nutrients present in mushroom & $3(15)$ & $17(85)$ & 14(70) \\
\hline 3 & Availability of spawn & $0(0)$ & $18(90)$ & $18(90)$ \\
\hline 4 & Methods of substrate making & $0(0)$ & $20(100)$ & $20(100)$ \\
\hline 5 & Moisture content & $2(10)$ & 18(90) & $16(80)$ \\
\hline 6 & Temperature to be maintained & $4(20)$ & $18(90)$ & $14(70)$ \\
\hline 7 & Spawning method & $2(10)$ & 19(95) & $17(85)$ \\
\hline 8 & No of holes per bag & $0(0)$ & $20(100)$ & $20(100)$ \\
\hline 9 & Sterilization of unit & $0(0)$ & $17(85)$ & $17(85)$ \\
\hline 10 & No of days in darkroom & $0(0)$ & 19(95) & 19(95) \\
\hline 11 & No of days in light room & $0(0)$ & 19(95) & 19(95) \\
\hline 12 & Harvesting methodology & $3(15)$ & $18(90)$ & $15(75)$ \\
\hline 13 & Preservating method & $2(10)$ & $16(80)$ & $14(70)$ \\
\hline 14 & Pests\& Disease management & $4(20)$ & $17(85)$ & $13(65)$ \\
\hline 15 & Importance of casing & $4(20)$ & $17(85)$ & $13(65)$ \\
\hline 16 & Marketing channels & $6(30)$ & $20(100)$ & $14(70)$ \\
\hline 17 & $\begin{array}{l}\text { Awareness and availability of loans } \\
\text { and subsidies from government }\end{array}$ & $0(0)$ & $19(95)$ & 19(95) \\
\hline 18 & Income & $0(0)$ & $19(95)$ & $19(95)$ \\
\hline 19 & BC Ratio & $0(0)$ & $19(95)$ & 19(95) \\
\hline 20 & Value addition to mushrooms & $4(20)$ & $17(85)$ & $13(65)$ \\
\hline Stat & tical Analysis & & & \\
\hline 1 & Mean & 9.5 & 91.5 & \\
\hline 2 & $\mathrm{~N}$ & 20 & 20 & \\
\hline$\overline{3}$ & Standard Deviation & 9.85 & 5.87 & \\
\hline 4 & $\mathrm{t}$ value & \multicolumn{2}{|c|}{$28.61 * *$} & \\
\hline
\end{tabular}

$(\%$ in parenthesis and $* *$ significant at $\mathrm{p}<0.01$ with $\mathrm{df}=19)$ 
Table.4 Adoption of mushroom cultivation by the trainees $(n=50)$

\begin{tabular}{|l|l|l|}
\hline Category & Frequency (n) & Percentage (\%) \\
\hline continued adopters & 27 & 54 \\
\hline discontinued & 13 & 26 \\
\hline non adopters & 10 & 20 \\
\hline
\end{tabular}

Table.5 Problem faced in adoption of mushroom cultivation $(\mathrm{n}=50)$

\begin{tabular}{|l|c|c|c|}
\hline Problem & $\begin{array}{c}\text { Continued } \\
\text { adopters }(\mathbf{n} 1=27)\end{array}$ & $\begin{array}{c}\text { Discontinued } \\
(\mathbf{n} 2=13)\end{array}$ & $\begin{array}{c}\text { Non adopters } \\
(\mathbf{n} 3=10)\end{array}$ \\
\hline Lack of proper infrastructure & - & - & $10(20)$ \\
\hline Non availability/ poor quality of spawn & $10(20)$ & $9(18)$ & - \\
\hline Non remunerative price & $17(34)$ & $4(8)$ & - \\
\hline
\end{tabular}

(\% written in parenthesis)

Table.6 Income of mushroom cultivation enterprise in proportion to family income $(n=27)$

\begin{tabular}{|c|}
\hline Increase in household income $(\%)$ \\
\hline $05-10$ \\
\hline $10-25$ \\
\hline $25-40$ \\
\hline $40-60$ \\
\hline $60-80$
\end{tabular}

\section{Economic benefits}

From the Table $6,45 \%$ of continued adopters had increased their family income by $60-80 \%$ followed by $30 \%$ of continued adopters had increased their family income by $5-10 \%$.

Vocational training programmes are conducted for interested farmers, women and rural youth for establishing their own agrienterprises for income generation. Evaluation of these training programmes conducted by the KVK, Utukur contributes to the academic output and also provides value judgment. The results of the study show that majority of the trainees were satisfied with the training provided by KVKs, Utukur and has resulted in significant knowledge gain of the trainees. (Singh et al., 2010 and Singh and Singh (2016))

\begin{tabular}{|c|c|}
\hline Frequency (n) & Percentage $(\%)$ \\
\hline 8 & 30 \\
\hline 2 & 7 \\
\hline 3 & 11 \\
\hline 2 & 7 \\
\hline 12 & 45 \\
\hline
\end{tabular}

The impact evaluation results show that the vocational training programmes conducted are augmenting the family income substantially. Kadapa was not known for mushroom cultivation prior to 2015. The efforts of the scientists at the KVK, Utukur in development of technologies for mushroom farming, and their dissemination through training programmes at $\mathrm{KVK}$ has resulted in making Kadapa recognized for mushroom production in the state of Andhra Pradesh. It has resulted in increase in family income by 60- $80 \%$. The socio-economic factors impacting that it had no influence on the adoption of mushroom cultivation. There are inconsistencies regarding the evidence about the relationship of age with adoption decision (Rogers, 2003; Pattanayak et al., 2003). Years of formal education, social status, upward social mobility, landholdings are positively 
related with adoption (Rogers, 2003). But our study shows that education and family income influenced the adoption decision in case of mushroom cultivation.

Farmer to farmer diffusion of mushroom technology was low. This is due to the fact that mushroom cultivation technology is complex. Only specialized hands-on training can make the farmers confident for adoption and use of technology. The other reasons for relatively low adoption of mushroom cultivation enterprise were Non remunerative price, Non availability/ poor quality of spawn, lack of proper infrastructure (20\%).

The results of this study cannot be generalized for all the vocational programmes implemented by the KVKs in India. Based on above discussion there is a strong evidence that results of our study can be generalized for the mushroom vocational programmes conducted KVK Utukur.

The findings of the study indicate that $\mathrm{KVK}$ is realizing the objectives of the vocational training programmes in terms of achieving desired outcomes and impacts. The trainees follow up may provide them timely guidance and avoid discontinuation of the enterprise. Trainees found these training highly satisfied and effective in meeting their expectations and they had gained knowledge in different aspects of mushroom farming. Non remunerative price, Non availability or poor quality of spawn were major hindrances in adoption of mushroom farming. Timely market information and availability of quality spawn may also improve the adoption of mushroom enterprise in the state Government should provide subsidy for establishing infrastructure and promote processing of mushrooms so that market prices may be stable and remunerative to mushroom growers. Thus, there is an urgent need to remove hindrances for accelerated adoption of mushroom enterprise for additional income generation.

\section{References}

Anonymous, 2015. Krishi Vigyan Kendras (KVKs) Agricultural Extension Division, Indian council of Agricultural Research, New Delhi. www.icar.org.in/ en/krishi- vigyan - kendra.htm.

Astroth, K. A., 1991. Prevention education programs: Can they be effective? Journal of Extension 29(2): 38-39.

Butler S. W., 1991. Integrating evaluation into teaching. Journal of Extension 29(2): 35-36.

Dharminder Singh., and Singh, K B. 2016. Evaluation of vocational training programme on mushroom cultivation. Indian journal of Economics and Development vol 12 (2): 387-392.

Goel, R R., and Sodhi, G P S, 2013.Evaluation of vocational training programmes organized on Mushroom farming by Krishi Vigyan Kendra, Patiala. Journal of Krishi Vigyan. 2 (1): 26-29.

Jahan, N M., Moonmoon, and shah, M MI, 2010. Grower's response to mushroom cultivation technologies disseminated by mushroom development project. Journal of Agriculture and social sciences. 6 (4): 96-100.

Johnson, E., and Verma, S. 1990. Are extension publications readable? Journal of Extension 28(2): 35.

Kuldeep Singh, Rajinder Peshin, Surinder Kaur Saini. 2010. Evaluation of Agricultural Vocational training programmes conducted by the Krishi Vigyan Kendras (Farm Science Centres) in Indian Punjab. Journal of Agriculture and Rural Development in the Tropics and Subtropics. Vol.111 (2): 65-77

Mahentesh Shirur., K. Manikandan and Wakcharure G C. 2016. Evaluation of 
National Training program on Mushroom cultivation technology for entrepreneurs. Mushroom Research 25(2): 147-152.

Nagaraj, R., P. Arunkumar, B.C. Hanumanthaswamy and Jyoti M. Rathod. 2017. Mushroom Production for Self Employment - An Impact Study. International Journal of Current Microbiology and Applied Science. 6(9): 2991-2997.

Pattanayak, S. K., Mercer, D. E., Sills, E. and Yang, J. C. 2003. Taking stock of agroforestry adoption studies. Agroforestry Systems, 57 (3), 173-186.

Praveen Kumar, Shruti Bharty, R K Singh, Krishna Kumar and Nidhika Rani. Impact of Oyster Mushroom (Pleurotus ostreatus) Training on Socio-Economic and Knowledge of tribal woman of Hazaribag, Jharkhand, India.
International Journal of Current Microbiology and Applied Sciences. Special issue 7: 1106-1111.

Rockwell, K., 1999. Does Extension make a difference: Measuring program outcomes. Unpublished, West Virginia University Jackson's Mill Conference Center.

Rogers. E.M., 2003. Diffusion of Innovations (5th ed.). Free Press, New York, USA.

Singh, R., and Singh, J.M. 2014. Marketing scenario and problems of mushroom growing in Punjab. Indian Journal of Economics and Development. 10 (1a):131-140.

Suvedi, M., 2011 Training manual on evaluating extension programs, Michigan State University. www. measextension.org/meas-offers/training offers/training/evaluatingextension program.

\section{How to cite this article:}

Gurram Ranjitha, Jillela Teza and Veeraiah, A. 2018. An Impact Study on Vocational Training Programme on Milky Mushroom Farming. Int.J.Curr.Microbiol.App.Sci. 7(11): 1475-1484. doi: https://doi.org/10.20546/ijcmas.2018.711.170 